\section{Dubious revolution}

\section{The Scientific Revolution \\ by Steven Shapin \\ University of Chicago Press: 1996. Pp. 225. \\ $\$ 22.95, \mathfrak{£} 15.95$}

\section{William Shea}

The Scientific Revolution, meaning roughly the period that runs from Copernicus to Newton, is so deeply entrenched in the literature that it is hard to believe that it was only given broad currency some 40 years ago in a book of that title by A. Rupert Hall. For nineteenth-century historians, the great revolutionary changes that catapulted Europe into the modern age were the Reformation and the Renaissance. For Hall, the breakthrough was the result of the twin advance of mathematical physics and factual discovery that began in the sixteenth century.

The shift may have been occasioned by a lessening of interest in religion and art, but it may also have been caused by growing concern over the status of modern science. When a society is perfectly satisfied with its method of knowing, it is not greatly exercised about the way it was first acquired. As long as science was considered to be the embodiment of rationality, its history was less an examination of actual events than a celebration of heroes and a quest for anticipations.

The belief that science was inevitably progressive was given canonical formulation by George Sarton in The Study of the History of Science, first published in 1936 and made popular in a paperback edition several years later. This view was based on the following premises. Definition: science is systematized positive knowledge or what has been taken as such at different ages and in different places. Theorem: the acquisition and systematization of positive knowledge are the only human activities that are truly cumulative and progressive. Corollary: the history of science is the only history that can illustrate the progress of mankind. In fact, progress has no definite and unquestionable meaning in fields other than science.

This naive view was echoed by philosophers of science who pointed out that consensus was possible in science but a forlorn hope elsewhere. They claimed this was the case because science dealt with matters of fact (as opposed to armchair theories) and resolved its disputes by invoking appropriate rules of inference instead of mere rhetoric.

Thomas S. Kuhn challenged the legitimacy of this rigid dichotomy between science and other kinds of knowledge in The Structure of Scientific Revolutions in 1962. He showed that the historical genesis of a theory is relevant to its content as well as its social acceptability. As a result, the canons of inductive logic so laboriously elaborated by philosophers of science began to look like parlour games. The pendulum swung from high-minded logical rigour to trendy sociological determination. Science, once the pure light of rationality, became a garish sign that was turned on and off by concealed pulsations in society.

What the exponents of the old and the new view had in common was a simplistic philosophy and a selective memory. Neither had a genuine desire to understand what had happened in the past. In their hurry to draw a moral for the present, they steamrollered their way through history and invented a mythical Galileo and a legendary Bacon.

Steven Shapin's book attempts to rise above the warring factions. He looks at seventeenth-century science with an eye for all the evidence, even when it leads him into places that are considered too murky by advocates of the linear progress of science or too rational by those who worship serendipity. His description of the Scientific Revolution is not arrived at by imposing a twentieth-century template on the seventeenth century, but by attending to the actual unfolding of the scientific process. The three chapters deal sequentially with what was known about the natural world in the seventeenth century, how that knowledge was secured, and what purposes it was intended to serve.

The first chapter covers topics included in most accounts of the Scientific Revolution, such as the Copernican theory and the mechanization of nature. The second and third chapters offer a sociological approach to the way the new learning was acquired and the goals for which it was intended.

Shapin offers a stimulating if controversial idea of how modern science was made and put to use. Many historians of science will feel that he does not do justice to the lasting contributions of Galileo, Boyle and Newton, but then, Shapin sees science as a system of provisional beliefs and not a growing body of truths about nature. Those who disagree with him will discover other ways of looking at the Scientific Revolution in the comprehensive and well-organized bibliographical essay at the end of the book.

Occasionally strident, but always well documented, this book will help scientists to understand why the Scientific Revolution is a more complex and more interesting phenomenon than many assume to be the case.

William Shea is at the Institute of the History of

Science, Université Louis Pasteur de Strasbourg, 7 Rue de l'Université, 67000 Strasbourg, France.

\title{
The art of burial in the land of the Pharaohs
}

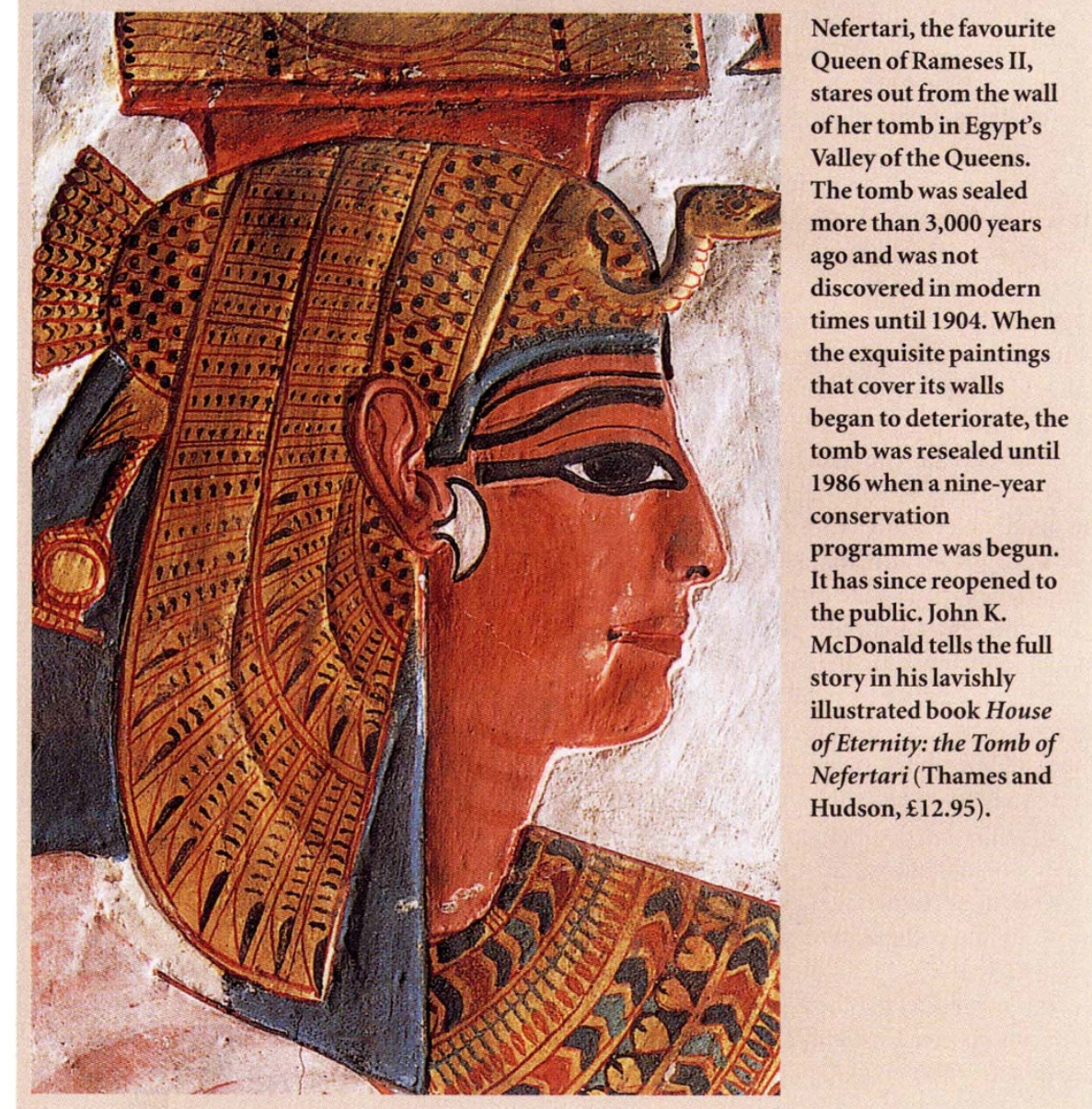

